\title{
Physiologic Studies of the Pulmonary Capillary Bed after Barium Sulfate Embolization*
}

\author{
Walter J. Daly and John A. Waldhausen \\ (From the Departments of Medicine and Surgcry and the Heart Research Center, Indiana \\ University School of Medicine, Indianapolis, Indiana)
}

\begin{abstract}
. 22 anesthetized dogs were given a barium sulfate suspension intravenously in a dose sufficient to double mean pulmonary artery pressure. $10 \mathrm{sec}$ breath-holding carbon monoxide diffusing capacity $\left(\mathrm{DL}_{\mathrm{CO}_{10}}\right)$ was measured before and after this standard embolization in each dog. No post-embolic decrease in $\mathrm{DL}_{\mathrm{CO}_{10}}$ was observed. In the study of this apparent paradox, it was found that the potential for further increase in $\mathbf{D L}_{\mathbf{C O}_{10}}$ during exercise remained after embolization. During rest prolongation of breath holding to $60 \mathrm{sec}$ decreased $\mathrm{CO}$ absorption significantly more in the embolized than in the nonembolized dogs. While $\mathrm{DL}_{\mathrm{CO}_{10}}$ was not affected by standard barium embolization, oxygen diffusing capacity was clearly decreased. The bronchial collateral circulation did not participate in preventing a $\mathbf{D L}_{\mathbf{C O}_{10}}$ decrease after embolization since surgical interruption of the bronchial circulation did not alter the response to barium. Microscopic examination of lung sections taken after standard embolization showed plugging of precapillary vessels in the 40-50 $\mu$ range. These studies suggest that acute precapillary embolic obstruction of vessels of this size interferes remarkably little with $\mathrm{CO}$ absorption over short periods of time, probably because of continued $\mathrm{CO}$ absorption in portions of the capillary net distal to the sites of impaction. The remarkable anastomotic nature of this capillary network with multiple sources of access possibly provides the anatomic basis for this observation. This study demonstrates a clear dissociation between acute changes in pulmonary vascular resistance and $\mathrm{DL}_{\mathrm{CO}_{10}}$-both during rest and exercise.
\end{abstract}

\section{Introduction}

Carbon monoxide absorption during a brief breath-holding period as described by Krogh and modified by Ogilvie, Forster, Blakemore, and Morton (1) has been used as a measure of the diffusing capacity of the lung $\left(\mathrm{DL}_{\mathrm{CO}}\right)$ and by in-

\footnotetext{
* Received for publication 18 April 1967 and in revised form 5 July 1967.

Reported in part at the 1966 meeting of the American Society for Clinical Investigation, Atlantic City, N. J.

This study was supported in part by research grants $\mathrm{H}-6228, \mathrm{H}-9243$, and $\mathrm{H}-4080$ from the National Heart Institute, U. S. Public Health Service and in part by the Indiana Heart Association.

Address requests for reprints to Dr. Walter J. Daly, Department of Medicine, Indiana University Medical Center, 1100 W. Michigan Street, Indianapolis, Ind. 46207.
}

ference as an index of the functional behavior of the pulmonary capillary bed in normal and abnormal situations $(2,3)$. The available evidence suggests that naturally occurring diseases which cause obliteration or obstruction of the pulmonary microcirculation decrease diffusing capacity (4-8), whereas acute vascular obstruction may occur with little or no change in $\mathrm{DL}_{\mathrm{CO}}(9,10)$. This study was designed to evaluate the effects of acutely produced precapillary microobstruction on changes in the pulmonary capillary bed as reflected in changes in $\mathrm{DL}_{\mathrm{CO}}$.

\section{Methods}

22 dogs with weights ranging between 16 and $26 \mathrm{~kg}$ were anesthetized intramuscularly with $2-3 \mathrm{mg}$ of morphine per $\mathrm{kg}$ followed $30-45 \mathrm{~min}$ later by $14-18 \mathrm{mg}$ of 
pentobarbital per $\mathrm{kg}$ given intravenously. The animals were ventilated with a cuffed endotracheal tube and a constant volume respirator. End tidal $\mathrm{CO}_{2}$ concentration was recorded continuously with an infrared $\mathrm{CO}_{2}$ analyzer. Respiratory volume and frequency were regulated to maintain end tidal $\mathrm{CO}_{2}$ concentration between 5 and $5.5 \%$. Catheters were placed in the main pulmonary artery, pulmonary "capillary wedge" position and the central aorta using fluoroscopic control. In each case pressures were accepted as "wedged" only if they were obtained with the catheter in a typically peripheral position relatively free of cardiac motion, if the pressure contour was compatible, and if either arterialized blood could be aspirated from the catheter or no blood at all was obtainable. A small polyethylene tube was inserted into a foreleg vein for easy injection of a barium sulfate suspension into the peripheral venous circulation.

In each phase of the study $10 \mathrm{sec}$ breath-holding carbon monoxide diffusing capacity, DL $\mathrm{CO}_{10}$, oxygen consumption, blood oxygen capacity, and intravascular pressures were measured. DL Co10 $_{10}$ was determined by a modified breathholding technique previously reported from this laboratory for use in dogs (11). With this system, the diffusing mixture, containing $1 \%$ neon and $0.5 \%$ carbon monoxide in air, is inspired from a bag-in-box apparatus, held and expired by regulating the pressure in an airtight plethysmographic box in which the dog rests on its back. The standard deviation of 10-15 such measurements in five dogs, each used on 4-5 different days, averaged 1.1 $\mathrm{ml} /(\mathrm{min} \times \mathrm{mm} \mathrm{Hg})$. In each case duplicate $\mathrm{DL}_{\mathrm{CO}_{10}}$ measurements and other measurements appropriate to the phase of the study were made before and just after intravenous administration of sufficient $30 \%$ suspension of barium sulfate to produce a doubling of the observed mean pulmonary artery pressure. This degree of embolization was used as a "standard embolus" load throughout the study. The actual quantity of barium required was highly variable. $1 \mathrm{ml}$ quantities of the suspension

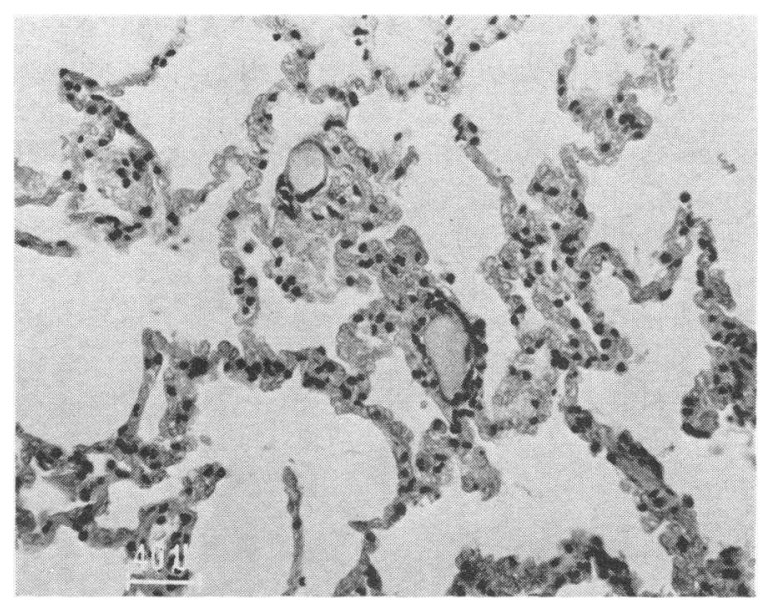

Fig. 1. Photomicrograph of a section of Lung obTAINED FROM A DOG SUBJECTED TO A STANDARD BARIUM EMBoLUs STUDY. Two barium filled vessels are included in the central portion of the field. $\times 250$. were given at 2 -min intervals until the desired doubling of pressure was observed. Intravascular pressures were integrated electronically and recorded photographically. Oxygen consumption was determined before and after barium embolization from a 3 or 4 min collection of expired gas. The gas volumes were measured in a Tissot spirometer and the expired oxygen concentrations were determined with a paramagnetic oxygen analyzer. Blood oxygen capacity was measured spectrophotometrically (12).

Barium sulfate particle size was determined with a series of standard sieves and microfilters. By weight, $0.02 \%$ of samples of barium passed through a standard 13.5-15 $\mu$ filter, $15 \%$ through a $37 \mu$ filter, and $82 \%$ through $105 \mu$ filter. Sections of lung were examined microscopically to estimate the site of vascular obstruction. Barium emboli were seen chiefly in arterioles or precapillaries in the $40-50 \mu$ range. No emboli larger than $75 \mu$ and none smaller than $20 \mu$ were identified (Fig. 1).

The project was divided into several phases:

(a) In the initial phase of the study, DLCo $0_{10}$, oxygen consumption, and intravascular pressures were measured before and after the standard barium embolization.

(b) Similar observations were made in three dogs previously prepared by bilateral "hilar stripping" to remove the branchial collateral circulation. In each case the animal had a staged operation in which one main stem bronchus was divided and reanastomosed. The hilar structures were stripped away, including the pulmonary arterial and venous adventitia. 3 days later the opposite lung was similarly prepared and 2 days later the animals were subjected to the barium study. After the experiment was terminated, the completeness of the bronchial artery interruption was tested by injection of a green radiopaque barium gelatin mixture into the dorsal aorta under a pressure of $200 \mathrm{~mm} \mathrm{Hg}$. The lungs were excised and observed for filling of the bronchial collateral circulation with the green barium mass both grossly and radiographically. In no case was any evidence of residual bronchial circulation detected. This technique had previously been used in this laboratory and shown regularly to outline the canine bronchial circulation.

(c) In seven dogs at rest the effect of prolonged breath holding during carbon monoxide absorption was tested. The rate of $\mathrm{CO}$ absorption during the standard $10 \mathrm{sec}$ breath hold was compared with $\mathrm{CO}$ absorption during a $60 \mathrm{sec}$ breath-holding period both before and subsequent to the standard embolization. During the prolonged breath-holding period the dogs were carefully observed for respiratory effort. The combination of deep inspiration and anesthesia was sufficient to suppress the respiratory drive for this length of time.

(d) In five dogs the effect of standard barium embolization on DLCo10 was compared with its effect on DLon. Oxygen diffusing capacity was determined by a modification of the method described by Bartels and coworkers (13). In each instance the animal breathed $40 \%$ oxygen for $15 \mathrm{~min}$ and $10 \%$ oxygen for $15 \mathrm{~min}$. The expirate was collected over the last $5 \mathrm{~min}$ of each period. 
TABLE I

Effects of standard barium sulfate embolization

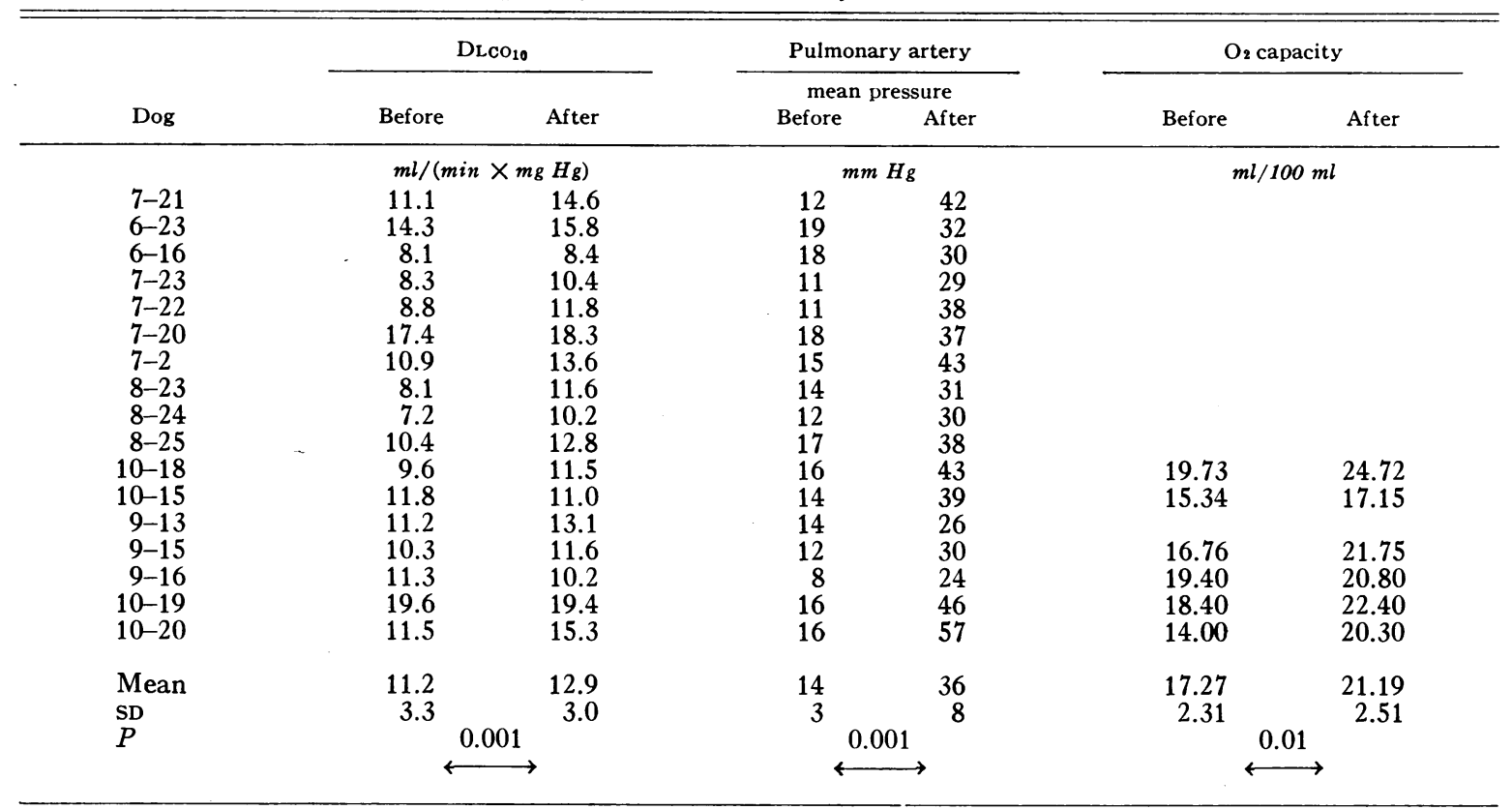

In this phase of the study the concentration of oxygen and carbon dioxide inspired and the concentrations of the expired samples were determined by the Micro-Scholander technique. Duplicate analyses of $\mathrm{CO}_{2}$ were required to check within $0.03 \mathrm{ml} / 100 \mathrm{ml}$ and oxygen within $0.04 \mathrm{ml} / 100 \mathrm{ml}$. Blood oxygen content and capacity were determined spectrophotometrically (12). In our laboratory, this method is sufficiently accurate to duplicate values within $0.06 \pm 0.06$ volumes $/ 100 \mathrm{ml}$. Blood $\mathrm{pH}$, $\mathrm{P}_{\mathrm{CO}_{2}}$ and $\mathrm{PO}_{2}$ were determined with appropriate electrodes. Actual mixed venous blood samples were obtained from the pulmonary artery catheter. The alveolar $\mathrm{Po}_{2}$ was calculated from the usual alveolar air equation, assuming ideal alveolar $\mathrm{PCO}_{2}=$ arterial $\mathrm{PCO}_{2}$. The quantity of veno-arterial shunting was estimated during $40 \% \quad \mathrm{O}_{2}$ breathing, assuming equilibrium of alveolar and endcapillary $\mathrm{Po}_{2}$. The diffusion component of the alveolararterial $\mathrm{PO}_{2}$ difference was determined during $10 \%$ oxygen breathing, assuming no change in veno-arterial shunting. Mean alveolar-capillary $\mathrm{Po}_{2}$ gradient was estimated with the Bohr integration expressed in Thews' nomogram (14). With this method oxygen diffusing capacity was determined and compared with $\mathrm{DL}_{\mathrm{CO}_{10}}$ both before and after standard embolization.

(e) Muscular exercise was induced in eight dogs with a modified Kao stimulator (C. B. Branch, Grand Prairie, Tex.) as previously described from this laboratory (11). Exercise sufficient to produce a fourfold increase in oxygen consumption was induced. DLco 10 was determined at rest and during the 4th to 6th min of such exercise both before and after standard barium embolization.

At the end of each experiment the animal was sac- rificed after having been anaesthetized intravenously with pentobarbital.

Paired comparison $t$ tests were done in all cases with the control observation from each animal used for comparison with its experimental observation.

\section{Results}

(a) After barium sulfate embolization in a quantity sufficient to double pulmonary artery pressure, $\mathrm{DL}_{\mathrm{CO}_{10}}$ increased from $11.2 \pm 3.3$ to $12.9 \pm 2.9 \mathrm{ml} /(\mathrm{min} \times \mathrm{mm} \mathrm{Hg})(P=0.001)$. Actually the mean pulmonary artery pressure increased from 14 to $36 \mathrm{~mm} \mathrm{Hg}$. Blood oxygen capacity increased from $17.27 \pm 2.31$ to $21.19 \pm$ $2.51 \mathrm{ml} / 100 \mathrm{ml}$ blood $(P=0.01)$ (Table I). Such increases in blood oxygen capacity occur in dogs subjected to a variety of stresses and can be related to contraction of the splenic reservoir (15). The magnitude of the increase in $\mathrm{DL}_{\mathrm{CO}_{10}}$ observed under these circumstances is appropriate for the observed increase in hemoglobin capacity available for carbon monoxide absorption. (This was established from the relationship, $1 / \mathrm{DL}_{\mathrm{L}}=$ $1 / \mathrm{Dm}_{\mathrm{M}}+1 / \mathrm{Vc} \theta$, standard values for $\mathrm{Vc}$ and $\mathrm{DM}$ previously established for dogs in this laboratory and appropriate corrections for $\theta$ based on the observed change in oxygen capacity.) 


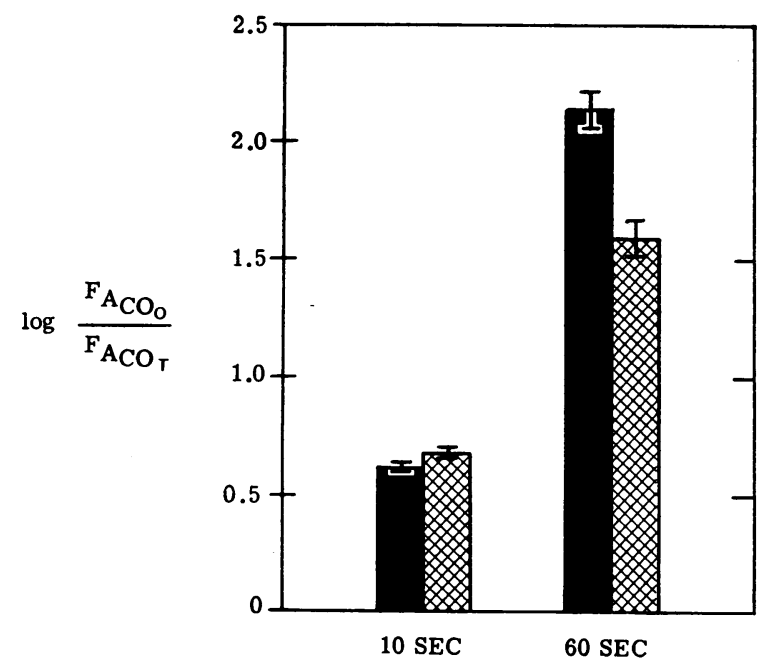

Fig. 2. DISAPPEARANCE OF CARBON MONOXIDE DURING BREATH HOLDING BEFORE AND AFTER STANDARD BARIUM SUlfate EmBolization. $\log _{\mathrm{e}}\left(\mathrm{FACO}_{0} / \mathrm{FACO}_{\mathrm{T}}\right)=$ the natural $\log$ of the ratio of initial alveolar $\mathrm{CO}$ concentration to final $\mathrm{CO}$ concentration. Solid bars indicate mean values of resting seven dogs before embolization and hatched bars indicate mean value of seven dogs after embolization. Brackets indicate standard error of the mean.

(b) In the three dogs that had bronchial artery stripping, $\mathrm{DL}_{\mathrm{CO}_{10}}$ averaged $11.5 \mathrm{ml} /(\mathrm{min} \times \mathrm{mm}$ $\mathrm{Hg})$ before and $11.4 \mathrm{ml} /(\mathrm{min} \times \mathrm{mm} \mathrm{Hg})$ after standard embolization.

(c) Fig. 2 compares the $\log _{\mathrm{e}}$ ratios of initial $\mathrm{CO}$ concentration over final $\mathrm{CO}$ concentration, $\log _{\mathrm{e}}\left(\mathrm{F}_{\mathrm{ACO}_{0}} / \mathrm{FA}_{\mathrm{AO}_{\mathrm{T}}}\right)$, before and after emboli during $10-$ and 60 -sec breath holds. Before embolization prolonging breath holding from 10 to $60 \mathrm{sec}$ increased $\log _{\mathrm{e}}\left(\mathrm{F}_{\mathrm{A}_{\mathrm{CO}}} / \mathrm{FA}_{\mathrm{CO}_{\mathrm{T}}}\right)$, from $0.618 \pm 0.017$ to $2.14 \pm 0.080$. After embolization, while the pulmonary artery pressure was increased from $13.7 \pm 2.9$ to $37.9 \pm 11.9 \mathrm{~mm} \mathrm{Hg}$, increasing the breath-holding period from 10 to $60 \mathrm{sec}$ increased $\log _{\mathrm{e}}\left(\mathrm{F}_{\mathrm{A}_{\mathrm{CO}}} / \mathrm{F}_{\mathrm{ACO}_{\mathrm{T}}}\right)$ from $0.685 \pm 0.015$ to 1.59 \pm 0.080 . The difference between the $\log _{\mathrm{e}}$ ratios at $60 \mathrm{sec}$ was significant at the $P=0.005$ level.

(d) In each of the five dogs in which the effect of standard embolization on $\mathrm{DL}_{\mathrm{O}_{2}}$ was compared with its effect on $\mathrm{DL}_{\mathrm{CO}_{10}}$, oxygen diffusing capacity was profoundly decreased by such embolization whereas $\mathrm{DL}_{\mathrm{CO}_{10}}$ remained unaffected. Table II shows the effects of standard barium embolization on $\mathrm{DL}_{\mathrm{O}_{2}}, \mathrm{DL}_{\mathrm{CO}_{10}}$, cardiac output, pulmonary artery pressure, pulmonary wedge pressure, and calculated pulmonary vascular resistance. Embolization decreased $\mathrm{DL}_{2}$ from $13.4 \pm 4.1 \mathrm{ml}$ $\mathrm{O}_{2} /(\min \times \mathrm{mm} \mathrm{Hg})$ to $6.2 \pm 3.4 \mathrm{ml} \mathrm{O}_{2} /(\min \times$ $\mathrm{mm} \mathrm{Hg})(P=0.01)$, whereas $\operatorname{DL}_{\mathrm{CO}_{10}}$, cardiac output, and wedge pressure were not appreciably changed. Pulmonary artery pressure increased from $15 \pm 2$ to $42 \pm 4 \mathrm{~mm} \mathrm{Hg}$ and calculated pulmonary vascular resistance from $3.2 \pm 1.8$ to $15.7 \pm 7.8(\mathrm{~mm} \mathrm{Hg} \times \mathrm{min}) /$ liter.

(e) During muscular exercise sufficient to increase the average oxygen consumption from 111 \pm 25 to $610 \pm 183 \mathrm{ml} / \mathrm{min}, \mathrm{DL}_{\mathrm{CO}_{10}}$ increased from $10.9 \pm 3.5$ to $22.5 \pm 10.8 \mathrm{ml} /(\min \times \mathrm{mm} \mathrm{Hg})$, while pulmonary artery pressure increased from $16 \pm 3$ to $31 \pm 12 \mathrm{~mm} \mathrm{Hg}$. After standard embolization, with a resting pulmonary artery mean pressure of $35 \pm 5 \mathrm{~mm} \mathrm{Hg}$, similar exercise increased pulmonary artery pressure to $50 \pm 16$ $\mathrm{ml} / \mathrm{min}$ and increased $\mathrm{DL}_{\mathrm{CO}_{10}}$ from $13.2 \pm 3.2$ to $20.4 \pm 6.6 \mathrm{ml} /(\min \times \mathrm{mm} . \mathrm{Hg}) \quad($ Table III $)$.

TABLE II

Comparison of effects of microemboli on $\mathrm{DL}_{\mathrm{O}_{2}}$ and $\mathrm{DL}_{\mathrm{CO}_{10}}$

\begin{tabular}{|c|c|c|c|c|c|c|c|c|c|c|c|c|}
\hline \multirow[b]{2}{*}{ Dog } & \multicolumn{2}{|c|}{$\mathrm{DLO}_{2}$} & \multicolumn{2}{|c|}{$\mathrm{DLCO}_{10}$} & \multicolumn{2}{|c|}{ Cardiac output } & \multicolumn{2}{|c|}{$\begin{array}{c}\text { Mean PA } \\
\text { pressure }\end{array}$} & \multicolumn{2}{|c|}{$\begin{array}{l}\text { Mean wedge } \\
\text { pressure }\end{array}$} & \multicolumn{2}{|c|}{$\begin{array}{l}\text { Pulmonary vascula r } \\
\text { resistance }\end{array}$} \\
\hline & Before & After & Before & After & Before & After & Before & After & Before & After & Before & After \\
\hline & \multicolumn{2}{|c|}{$m l /(\min \times m m H g)$} & \multicolumn{2}{|c|}{$m l /(\min \times m m H g)$} & \multicolumn{2}{|c|}{ liters/min } & \multicolumn{2}{|c|}{$m m H g$} & \multicolumn{2}{|c|}{$m m \mathrm{Hg}$} & \multicolumn{2}{|c|}{$(m m \underset{\text { liter }}{H g} \times \min ) /$} \\
\hline $\begin{array}{l}3-21 \\
3-7 \\
2-28 \\
4-4 \\
3-28\end{array}$ & $\begin{array}{r}12.9 \\
9.9 \\
13.5 \\
20.4 \\
10.5\end{array}$ & $\begin{array}{r}4.8 \\
7.8 \\
4.9 \\
11.1 \\
2.2\end{array}$ & $\begin{array}{r}8.7 \\
12.2 \\
10.3 \\
15.6 \\
10.0\end{array}$ & $\begin{array}{r}8.8 \\
12.1 \\
10.8 \\
17.2 \\
13.2\end{array}$ & $\begin{array}{l}3.25 \\
3.16 \\
1.55 \\
4.40 \\
2.52\end{array}$ & $\begin{array}{l}2.26 \\
3.23 \\
1.88 \\
5.26 \\
1.25\end{array}$ & $\begin{array}{l}12 \\
15 \\
15 \\
17 \\
16\end{array}$ & $\begin{array}{l}37 \\
48 \\
42 \\
41 \\
40\end{array}$ & $\begin{array}{l}7 \\
5 \\
6 \\
9 \\
5\end{array}$ & $\begin{array}{r}8 \\
5 \\
5 \\
10 \\
7\end{array}$ & $\begin{array}{l}1.5 \\
2.5 \\
5.8 \\
1.8 \\
4.3\end{array}$ & $\begin{array}{r}12.8 \\
13.3 \\
19.9 \\
5.9 \\
26.4\end{array}$ \\
\hline $\begin{array}{l}\text { Mean } \\
\text { SD } \\
P\end{array}$ & $\begin{array}{r}13.4 \\
4.2 \\
\quad 0 \\
\end{array}$ & $\begin{array}{r}6.2 \\
3.4 \\
1\end{array}$ & $\begin{array}{r}11.4 \\
2.7 \\
\text { N }\end{array}$ & $\begin{array}{r}12.4 \\
3.1\end{array}$ & $\begin{array}{l}2.98 \\
1.05\end{array}$ & $\begin{array}{l}2.78 \\
1.56\end{array}$ & $\begin{array}{r}15 \\
2 \\
0.0 \\
4\end{array}$ & $\begin{array}{r}42 \\
4 \\
01\end{array}$ & $\begin{array}{l}6 \\
2 \\
N\end{array}$ & IS $\begin{array}{r}7 \\
2\end{array}$ & $\begin{array}{l}3.2 \\
1.8 \\
0 . \\
\end{array}$ & $\begin{array}{r}15.7 \\
7.8 \\
25\end{array}$ \\
\hline
\end{tabular}

NS, not significant. 
TABLE III

Effects of microembolization on $\mathrm{DL}_{\mathrm{CO}_{10}}$ responses to exercise

\begin{tabular}{|c|c|c|c|c|c|c|c|c|c|c|c|c|c|c|c|c|}
\hline \multirow[b]{2}{*}{ Dog } & \multicolumn{4}{|c|}{$\mathrm{DLCO}_{10}$} & \multicolumn{4}{|c|}{$\mathrm{O}_{2}$ consumption } & \multicolumn{4}{|c|}{ Mean PA pressure } & \multicolumn{4}{|c|}{ Mean wedge pressure } \\
\hline & $\mathbf{R}$ & Ex & $\mathrm{BaR}$ & $\mathrm{BaEx}$ & $\mathbf{R}$ & Ex & $\mathrm{BaR}$ & $\mathrm{BaEx}$ & $\mathbf{R}$ & Ex & $\mathrm{BaR}$ & BaEx & $\mathbf{R}$ & Ex & BaR & $\mathrm{BaEx}$ \\
\hline & \multicolumn{4}{|c|}{$m l /(\min \times m m H g)$} & \multicolumn{4}{|c|}{$m l / \min$} & \multicolumn{4}{|c|}{$m m H_{g}$} & \multicolumn{4}{|c|}{$m m H g$} \\
\hline $\begin{array}{l}7-21 \\
6-23 \\
6-16 \\
7-20 \\
7-2 \\
8-23 \\
8-24 \\
8-25\end{array}$ & $\begin{array}{r}11.1 \\
14.3 \\
8.1 \\
17.4 \\
10.9 \\
8.1 \\
7.2 \\
10.4\end{array}$ & $\begin{array}{l}24.4 \\
17.6 \\
15.2 \\
43.7 \\
32.9 \\
13.4 \\
13.1 \\
19.8\end{array}$ & $\begin{array}{r}14.6 \\
15.8 \\
8.4 \\
18.3 \\
13.6 \\
11.6 \\
10.2 \\
12.8\end{array}$ & $\begin{array}{l}22.0 \\
24.8 \\
16.5 \\
33.6 \\
18.7 \\
13.6 \\
13.9 \\
20.0\end{array}$ & $\begin{array}{r}91 \\
123 \\
\\
132 \\
79 \\
150 \\
93 \\
108\end{array}$ & $\begin{array}{l}642 \\
328 \\
818 \\
860 \\
532 \\
554 \\
535\end{array}$ & $\begin{array}{r}107 \\
100 \\
185 \\
135 \\
160 \\
90 \\
132\end{array}$ & $\begin{array}{l}582 \\
317 \\
\\
838 \\
528 \\
540 \\
278 \\
458\end{array}$ & $\begin{array}{l}12 \\
19 \\
18 \\
18 \\
15 \\
14 \\
12 \\
17\end{array}$ & $\begin{array}{l}28 \\
27 \\
22 \\
40 \\
54 \\
17 \\
34 \\
25\end{array}$ & $\begin{array}{l}42 \\
32 \\
30 \\
37 \\
43 \\
31 \\
30 \\
38\end{array}$ & $\begin{array}{l}58 \\
55 \\
40 \\
58 \\
82 \\
35 \\
38 \\
33\end{array}$ & $\begin{array}{l}5 \\
3 \\
4 \\
6 \\
5 \\
3 \\
4 \\
6\end{array}$ & $\begin{array}{l}6 \\
4 \\
3 \\
5 \\
4 \\
4 \\
6\end{array}$ & $\begin{array}{l}4 \\
5 \\
5 \\
5 \\
4 \\
3 \\
4 \\
4\end{array}$ & $\begin{array}{l}3 \\
6 \\
4 \\
4 \\
5 \\
6 \\
7 \\
4\end{array}$ \\
\hline $\begin{array}{l}\text { Mean } \\
\mathrm{SD} \\
P\end{array}$ & $\begin{array}{r}10.9 \\
3.5\end{array}$ & $\begin{array}{l}22.5 \\
10.8\end{array}$ & $\begin{array}{r}13.2 \\
3.2\end{array}$ & $\begin{array}{r}20.4 \\
6.6\end{array}$ & $\begin{array}{r}111 \\
25\end{array}$ & $\begin{array}{r}610 \\
183\end{array}$ & $\begin{array}{r}130 \\
34\end{array}$ & $\begin{array}{l}506 \\
186\end{array}$ & $\begin{array}{r}16 \\
3\end{array}$ & $\begin{array}{r}31 \\
12 \\
0 .\end{array}$ & $\begin{array}{r}35 \\
5 \\
01\end{array}$ & $\begin{array}{l}50 \\
17\end{array}$ & $\begin{array}{l}4 \\
1\end{array}$ & $\begin{array}{l}4 \\
1 \\
N\end{array}$ & $\begin{array}{r}4 \\
1 \\
\mathrm{TS}\end{array}$ & $\begin{array}{l}5 \\
1\end{array}$ \\
\hline
\end{tabular}

$R$, rest; Ex, exercise; BaR, rest after barium sulfate; BaEx, exercise after barium sulfate; NS, not significant.

The two resting $\mathrm{DL}_{\mathrm{CO}_{10}}$ averages and two exercise $\mathrm{DL}_{\mathrm{CO}_{10}}$ averages were not statistically different nor was the exercise $\mathrm{DL}_{\mathrm{CO}_{10}}$ increment before and after barium statistically different. Pulmonary capillary wedge pressures were not affected by exercise either before or after embolization.

\section{Discussion}

A variety of studies have examined the clinical usefulness of $\mathrm{DL}_{\mathrm{CO}}$ measurements. In general those conditions characterized by obstruction and obliteration of the pulmonary capillary bed have been associated with decreases in $\mathrm{DL}_{\mathrm{CO}_{10}}$ (4-8). An attempt was made to simulate these conditions acutely by producing precapillary pulmonary vascular obstruction sufficient to induce meaningful increases in pulmonary vascular resistance. Barium sulfate suspension was used in this study and has been used by other investigators $(16,17)$. Knisely, Wallace, Mahaley, and Satterwhite observed the lung directly during embolization with a variety of particle sizes and materials, including barium sulfate. They observed that most artificial embolic materials were heavily coated with thrombotic material by the time they lodged in the pulmonary vessels so that their original size could not be the sole determinant of the size of the vessel embolized (16). They also observed that arteriolar and precapillary emboli did not always impede flow or empty vessels distal to the obstruction because of extensive collateral circulation through the capillary network. Pump has observed that obstruction at or distal to arterioles of the third division (his estimate, $119 \mu$ diameter) would have little effect on the distal vascular bed because of the continuity and numerous anastomoses between different regions of the capillary net (18). Knisely and coworkers' observations also demonstrated that fine particles such as barium sulfate can pass completely through the lung. Whether a portion of the administered barium sulfate passes through the lung is not critical to the present study, since the dose of embolic material used was determined solely by the pressure effect observed in each individual animal. Microscopic examination of the sections of lung obtained after this standard embolization showed no evidence of capillary obstruction and rare obstruction of vessels larger than $60 \mu$, but did show extensive plugging at the $40-50 \mu$ level. Barium plugs that did not completely fill the lumen of the affected vessel were not identified.

The results of the present study clearly demonstrate a dissociation between acute increases in pulmonary vascular resistance induced by microembolization and $\mathrm{DL}_{\mathrm{CO}_{10} \text {. This dissociation is }}$ consistent with the observations of Williams and Sobol who used $60-\mu$ glass beads and found no appreciable change in steady-state $\mathrm{DL}_{\mathrm{Co}}$ when pulmonary artery pressure was increased by microembolization (10). Two alternative explanations are available for the somewhat paradoxical preservation of a reasonably normal $\mathrm{DL}_{\mathrm{CO}_{10} \text { o }}$. Either the unaffected capillary bed enlarged and became more active in $\mathrm{CO}$ absorption, or the 
capillary bed distal to the emboli remained active in $\mathrm{CO}$ absorption, or both. Mechanisms are available to initiate expansion of the unembolized capillary bed. As during normal exercise, the increased pulmonary artery pressure after emboli might open portions of the bed not available to $\mathrm{CO}$ during rest, thus preventing a $\mathrm{DL}_{\mathrm{CO}}$ decrease as the pulmonary vascular resistance is increased by barium embolization. Preservation of the capability to increase $\mathrm{DL}_{\mathrm{CO}_{10}}$ further during muscular exercise suggests that the unchanged postembolic $\mathrm{DL}_{\mathrm{CO}_{10}}$ is not solely a utilization of the extensive pulmonary capillary reserve but that the capacity for still further expansion of the capillary bed remains after this degree of embolization. Yet, increases in pulmonary vascular resistance of the degree observed suggest obstruction of substantially more than $50 \%$ of the pulmonary vascular bed $(19,20)$. Nevertheless, evidence other than continued $\mathrm{DL}_{\mathrm{CO}}$ increases during exercise is required to establish whether $\mathrm{CO}$ absorption takes place in the capillary net distal to sites of obstruction.

It seems well established that breath-holding carbon monoxide absorption over short periods of time is independent of blood flow if pulmonary vascular pressures do not change (21). Consequently one may postulate continued $\mathrm{CO}$ absorption during a $10 \mathrm{sec}$ breath hold in portions of the pulmonary capillary net that remain filled with blood after barium embolization. Both Knisely and coworkers (16) and Staub (22), using different techniques, have observed the continued presence of red cells in pulmonary capillaries after flow has stopped, and Staub has pointed out the possibility of continued $\mathrm{CO}$ absorption by those stagnant red cells, causing paradoxically high $\mathrm{DL}_{\mathrm{CO}}$ and gross dissociation of $\mathrm{DL}_{\mathrm{CO}}$ and pulmonary capillary flow. If this were indeed the reason for the absence of decreases in $\mathrm{DL}_{\mathrm{CO}_{10}}$ after microembolization, one would expect the rapid build-up of carbon monoxide back pressure resisting diffusion in areas of stagnant or sluggish flow distal to microemboli. During more prolonged breath holds, therefore, CO absorption should decrease more rapidly after emboli. Piiper has examined the theoretical and practical implications of uneven distribution of diffusing capacity and its effects on carbon monoxide absorption during breath-holding periods of variable length and has concluded that the decrease in apparent $\mathrm{DL}_{\mathrm{CO}}$ as the duration of breath holding is increased is a manifestation of uneven distribution of diffusing capacity. The development of focal increases in capillary Pco is a part of such unevenness (23). In this study, when the breath-holding period was prolonged from 10 to $60 \mathrm{sec}$, $\mathrm{CO}$ absorption did decrease appreciably more after embolization than before embolization. This observation favors the thesis that after emboli the apparent paradox of an unaffected $\mathrm{DL}_{\mathrm{CO}_{10}}$ may indeed depend upon $\mathrm{CO}$ absorption in areas of relatively no flow.

Since extremely low partial pressures of $\mathrm{CO}$ are present in the alveoli and the hemoglobin $\mathrm{CO}$ capacity is relatively so great, $\mathrm{CO}$ absorption is limited by blood flow only at the lowest flow rates or after more prolonged exposure with development of significant capillary Pco. Oxygen absorption on the other hand at ambient $\mathrm{Po}_{2}$ is, of course, flow dependent. In this study it was shown that embolization with barium, although leaving $\mathrm{DL}_{\mathrm{CO}_{10}}$ and total blood flow unaffected, did decrease $\mathrm{DL}_{\mathrm{O}_{2}}$ profoundly. This again is quite compatible with the concept that carbon monoxide was continuing to be absorbed in areas of the pulmonary capillary bed which were filled but very poorly perfused while $\mathrm{DL}_{\mathrm{O}_{2}}$ became a much more sensitive index of gross unevenness of flow distribution. In the absence of a decrease in total blood flow, the decrease in $\mathrm{DL}_{\mathrm{O}_{2}}$ after emboli probably depends upon the development of regional variations in capillary transit time with incomplete equilibration of alveolar end capillary $\mathrm{Po}_{2}$. This mechanism has been examined in detail by Staub (24). If on the other hand $\mathrm{DL}_{\mathrm{CO}_{10}}$ were maintained at a relatively normal level after emboli by utilization of the usually inactive portions of the capillary bed, i.e. by opening new areas of the net, capillary transit times and $\mathrm{DL}_{\mathrm{O}_{2}}$ should have been relatively unaffected after embolization. This study did not examine exercise $\mathrm{DL}_{\mathrm{O}_{2}}$ after emboli, but prediction based on this thesis requires even further decrease in $\mathrm{DL}_{\mathrm{O}_{2}}$ during exercise.

The bronchial circulation did not contribute to the postembolic normal $\mathrm{DL}_{\mathrm{CO}_{10}}$ level since the phenomenon was not affected after interruption of the bronchial arteries. It is known that bronchial collateral flow normally increases when pulmonary artery flow decreases and may participate in gas exchange (25). However, this was not requisite 
for the maintenance of the normal $\mathrm{DL}_{\mathrm{CO}_{10}}$ after standard embolization.

Although the normal increase in breath holding DL $\mathrm{L}_{\mathrm{Co}}$ during muscular exercise is not totally explained, the available evidence suggests: $(a)$ that it is dependent either upon dilation of previously functioning capillaries or recruitment of ones previously empty of hemoglobin; $(b)$ that this enlargement of the effective pulmonary capillary bed is dependent upon the effects of increased pressure within the pulmonary capillary bed. The results of the present study indicate that precapillary obstruction to flow may increase vascular resistance but that the collateral access to the capillary network may be adequate to permit a normal $\mathrm{DL}_{\mathrm{CO}}$. After standard barium emboli, the exercise increment in vascular pressure remains effective in making available a larger capillary bed for $\mathrm{CO}$ absorption, a much greater absolute pressure being required however.

An anatomic basis for the physiologic observations observed in this study has been demonstrated by numerous investigators who have described the extensive collateral communication within the pulmonary capillary network $(16,18,22,26)$. This network is so liberally supplied with collateral sources that arteriolar obstruction at one site may very possibly leave the distal pulmonary capillary bed unaffected.

This study then demonstrates: $(a)$ that changes in $\mathrm{DL}_{\mathrm{CO}_{10}}$ may be dissociated from acute changes in pulmonary vascular resistance induced by a standardized barium sulfate embolus; $(b)$ that the continued $\mathrm{CO}$ absorption is not dependent upon bronchial collateral flow but probably occurs in capillaries distal to the site of obstruction unevenly perfused but filled through collateral channels. Increased participation of portions of the capillary network not normally involved in $\mathrm{CO}$ absorption at rest cannot be excluded but does not seem to be the sole basis for the continued ability to absorb $\mathrm{CO}$ at a normal rate over short periods of time. During further increases in pulmonary artery pressure induced by exercise, these collateral channels are sufficient to induce normal increases in exercise $\mathrm{DL}_{\mathrm{CO}_{10}}$. In all probability the maintenance of the normal $\mathrm{DL}_{\mathrm{CO}_{10}}$ observed in this study depends upon the remarkable pulmonary capillary anastomosing network with access to this network from a variety of sources.
The acute precapillary obstruction produced in these dogs is different from the naturally occurring diseases associated with obstruction and obliteration of the microvascular bed because in these dogs destruction of the distal capillary bed does not occur. It is doubtful that an exact human counterpart for this phenomenon will be discovered except rarely in situations where microembolization may be encountered.

In their review of 31 patients with "alveolarcapillary block" Marks, Cugell, Cadigan, and Gaensler report comparison of $\mathrm{DL}_{\mathrm{CO}_{10}}$ and $\mathrm{DL}_{\mathrm{O}_{2}}$ in 14 patients (4). These 14 patients can be clearly divided into two groups, those with comparable and low $\mathrm{DL}_{\mathrm{O}_{2}}$ and $\mathrm{DL}_{\mathrm{CO}_{10}}$ values and those with reasonably normal $\mathrm{DL}_{\mathrm{CO}_{10}}$ yet low $\mathrm{DL}_{\mathrm{O}_{2}}$. Those patients with least reduction of $\mathrm{DL}_{\mathrm{CO}_{10}}$ had the greatest discrepancy between $\mathrm{DL}_{\mathrm{CO}_{10}}$ and $\mathrm{DL}_{\mathrm{O}_{2}}$. Those patients were also classed as least severe and in general had evidence of the disease for a shorter time. This consideration of their data in the light of the present study suggests that this group of patients may indeed represent a clinical setting in which there are areas of the capillary bed accessible to CO but with sufficient disparity of capillary transit times to impair $\mathrm{DL}_{\mathrm{O}_{2}}$.

\section{References}

1. Ogilvie, C. M., R. E. Forster, W. S. Blakemore, and J. W. Morton. 1957. A standardized breath holding technique for the clinical measurement of the diffusing capacity of the lung for carbon monoxide. J. Clin. Invest. 36: 1 .

2. Daly, W. J., S. T. Giammona, J. C. Ross, and H. Feigenbaum. 1964. Effects of pulmonary vascular congestion on postural changes in the perfusion and filling of the pulmonary vascular bed. J. Clin. Invest. $43: 68$.

3. Steiner, S. H., R. Frayser, and J. C. Ross. 1965. Alterations in pulmonary diffusing capacity and pulmonary capillary blood volume with negative pressure breathing. J. Clin. Invest. 44: 1623.

4. Marks, A., D. W. Cugell, J. B. Cadigan, and E. A. Gaensler. 1957. Clinical determination of the diffusing capacity of the lungs. Comparison of methods in normal subjects and patients with "alveolar-capillary block" syndrome. Am. J. Med. 22: 51.

5. Burrows, B., J. E. Kasik, A. H. Niden, and W. R. Barclay. 1961. Clinical usefulness of the singlebreath pulmonary diffusing capacity test. $A m$. Rev. Respirat. Diseases. 84 : 789. 
6. Burgess, J. H., and J. M. Bishop. 1963. Pulmonary diffusing capacity and its subdivisions in polycythemia vera. J. Clin. Invest. $42: 997$.

7. Auchincloss, J. H., Jr., and R. Gilbert. 1964. Singlebreath diffusing capacity as an aid in evaluation and prognosis of cardiopulmonary disease. $\mathrm{Am}$. Rev. Respirat. Diseases. 90 : 28.

8. Sackner, M. A., N. Akgun, P. Kimbel, and D. H. Lewis. 1964. The pathophysiology of scleroderma involving the heart and respiratory system. Ann. Internal Med. 60: 611 .

9. Colp, C. R., and M. H. Williams, Jr. 1962. Pulmonary function following pulmonary embolization. Am. Rev. Respirat. Diseases. 85 : 799.

10. Williams, M. H., Jr., and B. J. Sobol. 1963. Effects of a systemic A-V fistula and of pulmonary embolization on diffusing capacity. J. Appl. Physiol. 18 : 553 .

11. Brashear, R. E., J. C. Ross, and W. J. Daly. 1966. Pulmonary diffusion and capillary blood volume in dogs at rest and with exercise. J. Appl. Physiol. $21: 516$.

12. Hickam, J. B., and R. Frayser. 1949. Spectrophotometric determination of blood oxygen. J. Biol. Chem. 180: 457.

13. Bartels, H., R. Beer, E. Fleischer, H. J. Hoffheinz, J. Krall, G. Rodewald, J. Wenner, and I. Witt. 1955. Bestimmung von Kurzschlussdurchblutung und Diffusionskapazität der Lung bei Gesunden und Lungenkranken. Pfluegers Arch. Ges. Physiol. 261: 99.

14. Thews, G. 1959. Ein Nomogramm zur einfachen Bestimmung des $\mathrm{O}_{2}$-Diffusionfaktors $\left(\mathrm{O}_{2}\right.$-Diffusionskapazität) der Lunge. Pflugers Arch. Ges. Physiol. 268 : 281.

15. Cruickshank, E. W. H. 1926. Of the output of haemoglobin and blood by the spleen. J. Physiol. (London). $61: 455$.

16. Knisely, W. H., J. M. Wallace, M. S. Mahaley, Jr., and W. M. Satterwhite, Jr. 1957. Evidence, in- cluding in vivo observations, suggesting mechanical blockage rather than reflex vasospasm as the cause of death in pulmonary embolization. $\mathrm{Am}$. Heart J. $54: 483$.

17. Halmagyi, D. F. J., and H. J. H. Colebatch. 1961. Cardiorespiratory effects of experimental lung embolism. J. Clin. Invest. 40: 1785.

18. Pump, K. K. 1966. The circulation in the peripheral parts of the human lung. Diseases Chest. 49 : 119.

19. Cournand, A., R. L. Riley, A. Himmelstein, and R. Austrian. 1950. Pulmonary circulation and alveolar ventilation-perfusion relationships after pneumonectomy. J. Thoracic. Cardiovascular Surg. 19: 80.

20. Lategola, M. T. 1958. Pressure-flow relationships in the dog lung during acute, subtotal pulmonary vascular occlusion. Am. J. Physiol. 192: 613.

21. Lawson, W. H., Jr., H. N. Duke, R. W. Hyde, and R. E. Forster. 1964. Relationship of pulmonary arterial and venous pressure to diffusing capacity. J. Appl. Physiol. 19 : 381.

22. Staub, N. C. 1963. The interdependence of pulmonary structure and function. Anesthesiology. 24 : 831.

23. Piiper, J., and R. S. Sikand. 1966. Determination of $\mathrm{D}_{\text {co }}$ by the single breath method in inhomogeneous lungs: theory. Respirat. Physiol. $1: 75$.

24. Staub, N. C. 1963. Alveolar-arterial oxygen tension gradient due to diffusion. J. Appl. Physiol. 18: 673.

25. Mandelbaum, I., and S. T. Giammona. 1964. Bronchial circulation during cardiopulmonary bypass. Ann. Surg. 164 : 985.

26. Irwin, J. W., W. S. Burrage, C. E. Aimar, and R. W. Chesnut, Jr. 1954. Microscopical observations of the pulmonary arterioles, capillaries, and venules of living guinea pigs and rabbits. Anat. Record. $119: 391$. 